\title{
TIME AND CHAOS: THE “IMAGINATION OF POSSIBILITIES" AND THE MEDIA
}

\author{
Gustavo Castro \& Florence Dravet
}

\begin{abstract}
This article proposes a reflection about the notion of time and its relation to the media based on the complex thinking paradigm and the transdisciplinary perspective. Departing from reflections about literary and cinematographic narratives, our objective is to examine how the notion of time mediates the concept of comprehension of space/time as well as of the aesthetic perception of the world between order and chaos. We relied on the dialogue between science and narrative and on modern physics for concepts of time, order and chaos. Our conclusions point to three ideas: 1) the constant remembrance of catastrophe is an obsessive intimate theme which presents itself through an artistic and mediatic narrative; 2) the expression of catastrophic obsession partially satisfies the current humanity's affection for horror and 3) the imaginary of catastrophe traverses time and space, being transdisciplinary.
\end{abstract}

\section{Tempo E CaOS: A “imaginaÇão dos PoSsíveis” E OS MÉdia}

\begin{abstract}
Resumo
Este artigo propõe uma reflexão sobre a noção de tempo e suas relações com os média, a partir dos estudos da complexidade e numa perspetiva transdisciplinar. Iniciando com reflexões sobre narrativas literárias e cinematográficas, o nosso objetivo é perceber como a noção de tempo é mediadora da compreensão da realidade espaço/tempo e da perceção estética do mundo entre ordem e caos. Recorremos ao diálogo entre ciência e narrativa e ao pensamento da física moderna sobre os conceitos de tempo, ordem e caos. As nossas conclusões apontam para três ideias: 1) a constante rememoração da catástrofe é um tema íntimo obsessivo que se apresenta através da narrativa artística e mediática; 2) a expressão da obsessão catastrófica vem suprir parcialmente o afeto pelo horror da humanidade atual e 3) o imaginário da catástrofe atravessa tempo e espaço e é transdisciplinar.
\end{abstract}




\section{INTRODUCTION}

The relation between time, media and chaos integrated a research program developed inside the so-called studies of complexity, starting from the development of ideas of "order from noise" ("ordre à partir du bruit") defended by Henri Atlan (1992), and of "complexity of disorder", mentioned for the first time in 1948, by Warren Weaver, in the famous article "Science and complexity". The concept of media became important in the studies of complexity due to the perception of the "huge amount of interactions and interferences among a large number of units that defied our possibilities of calculation" (Pessis-Pasternak, 1993, p. 14).

Norbert Wiener and Ross Ashby, founders of the cybernetics, worked to promote the notion of complexity. John von Neuman ended up revealing the links which bonded phenomena of auto-organization to those of interactions. Based on the perception of these links Edgar Morin (1987) proposed a tetragram (order/disorder/interaction/auto-organization) as a conceptual articulation that permits conceiving communication as dialogic, regulated first by uncertainty, with a permanent tendency to chaos and disorder, close to what Prigogine designated as flotation, a "mechanism of irreversibility: once established, it differs from what it previously was" (Prigogine quoted in Pessis-Pasternak, 1993, p. 43).

In this article, we intend to discuss the notion of time, based on its closeness to catastrophe, as well as the notion of media, departing from its relation to literature.

The theoretical-methodologic approach used springs from the premise that the narratives, imaginaries, poems, romances and tales are discourses engendered in our daily life, as well as in the various media which involve us, from the primary (the ones of present time and body), going through the secondary (those in which the sender uses a technical apparatus to send messages, elongating perception of time), to the tertiary (in which the sender and receiver need technical apparatus and can exchange messages without being simultaneously present, shortening time and making communication faster) (Romano 1993). Our presentation method and exploration of the material will be descriptive, interpretative and critical, and we intend to prioritize the analysis of time, relating it to the notion of chaos and catastrophe in the narratives of Cosmicomics (1992) and T Zero (1995), by Italo Calvino, in the movie Melancholia, directed by Lars Von Trier (2011), and also in the interpretations by the physicist and Nobel Chemistry Prize winner Ilya Prigogine'. Our objective is to show how the notion of time in literature may mediate our comprehension of the reality of space/time and of the world, collaborating with the transdisciplinary research program in the studies of complexity.

From the epistemological point of view as well as from the methodological view, the studies of complexity and this article seek to establish a dialogue between science and art, understanding them both as a transdisciplinarity field itself. It is our understanding that literature and cinema always embody models of society, if not the ones we aspire,

(1917-2003). Russian physicist-chemist with Belgian citizenship, specialist in non-equilibrium thermodynamics. Nobel Chemistry Prize winner (1977) for his contribution to the study of non-equilibrium thermodynamics and theory of dissipative structures. Was the founder and first director (1967) of the llya Prigogine Center of Studies in Statistical Mechanics, Thermodynamics and Complex Systems, University of Texas, Austin. 
at least the ones we have and construct. They gather in themselves the multiplicity of knowledges, the ethical search and the aesthetic cosmovision of life. Science and art are intercommunicating knowledges, two ways of observing the world, opponent forces that may form a complementarity or the same unit of knowledge. They can't go on artificially separated, but must, beforehand, reintroduce man into the complexity of the world. If, on the one hand, scientific knowledge feeds doubt and creates hierarchies by raising fundamental questions, on the other, artistic knowledge illuminates and brightens reality, placing or returning man to his vital context. The need to make science and art communicate comes from the recognition that both are knowledge systems relevant to society. While science deals with combined and systematic efforts to raise experience and develop appropriate concepts for its comprehension, art presents us with individual efforts, more intuitive, to evoke feelings which reminds us of the entirety of the human situation.

\section{The order of time according to Ilya Prigogine and Italo Calvino}

The human capacity to imagine the worse has no limits. We know that the theme of catastrophe is not new. It is, in fact, as ancient as fear itself. It is possible to find the subject in, at least, two dialogues by Plato, in Timaeus and in Critias (written circa 360 B.C.). In Critias we found the following account: It is said that an ancestor of his grandfather, who had visited Egypt and talked to the elders, masters of ancient memories, used to say that catastrophe was something deriving the cosmos and, therefore, was also among men. It was a phenomenon which occurred from time to time. Initially, Plato says, it was believed that catastrophe was a myth, but it

means the decline of bodies which move around the Earth and in the heavens; a recurrent conflagration, which occurs at long time intervals; when this happens, those who live in mountains and other dry places are more likely to suffer destruction than those who live next to rivers, lakes and sea. However, on the other hand, when the gods purge the earth by water [and not by fire, like Faetonte], then the shepherds, the mountain dwellers, are the survivors and those who perish are the ones who live in cities, next to rivers and fountains, on the coast; they are taken by floods, submerge in the ocean. (...) While you [Greeks] and other nations maintain scriptures and only these registries that are interest of the state, at the present moment, you ignore that pestilence [catastrophe] may be coming from the heavens to decimate everyone and leave only those that are devoid of letters and education and, thus, you will have to start all over again, like children, with no knowledge of what has happened in ancient times, among us [Egyptians] and you yourselves [Greeks]. (Plato, 2010, p. 88)

In this quote, we note that "catastrophe" is not treated as an invention, but as something which "occurs at long time intervals". It appears as a reality lived by the ancient people, which reveals itself, at times, as fire or as water. These events serve so that 
the Earth and humanity may "start over again like children". The events described in this fragment by Plato feed, for at least more than two millennia - through philosophical means - the image-idea of catastrophe. They feed the pathos of the end present in all of us, that is, the affection for entropy, the sensation of misfortune, sometimes the passion for the fall.

According to llya Prigogine (1996), the "imagination of possibilities" and the speculation about what is to come are founding traces of human intelligence. Antonio Maza considers the same in his article about "The expressive power of the possible worlds theory in videogames" (2015) when he assumes that the theory of possible worlds is present in the literary and narrative context in various authors and in various manners: in objective reality with texts which are historical or journalistic, in texts of credible fiction, in unbelievable fictional worlds and in the multiple interpretations of current worlds.

While the Egyptians and Greeks imagined destruction by water and by fire, the imaginary of Italo Calvino depicted a narrative in which space and time are diluted and crumble at every moment and everywhere. The hero of The cosmicomics is Qfwfq, anamorphic, continuously changing his form, at times advanced in complexity and at others not. This romance, written in the 1970's, contains an image-idea of catastrophe, of order and disorder, which is worth analyzing.

Things last while the sun lasts, so says the hero-narrator. People are smoothed and brushed by the winds of time, because time is nothing but a bet: there is the short and long-term time. The events simmer with multiplicity and density. The anamorphic character Qfwfq knows immortality, he is beyond time under the forms of metamorphosis: he was, throughout 50 million years, a sequence of various dinosaurs; experimented with forms such as the tadpole, the atom, the horse, the elder; he knew Justinian's empire, saw the silkworm being taken from China to Constantinople, among other adventures. Other characters, such as his brother Rwzfs, did not want to try different forms, remaining nickel for his entire life. Mr. Hnw, in turn, went through existence wishing to become a horse. Qfwfq considers the platypus, the giraffe, the crocodile and the dinosaur sublime. "World memory", title of the first part of The new cosmicomics [T Zero in other translations], describes stories interspersed with cosmological, philosophical and existential reflections:

we asked what was the destiny of the universe, and the oracles of thermodynamics answered: all existing forms will dissolve in a flame; there is no presence which can be saved from disorder without returning to corpuscles; time is a perpetual and irreversible catastrophe. (Calvino, 1995, p. 127)

Catastrophe appears as a reason for the need to appreciate the order. To find balance in the universe, in a form which appears formless, is not an easy task. Qfwfq prefers to risk himself in the geometry of crystals, love affairs, games and spirals. The priority of order must be given to the love model, that which contains Eros in its structure. The

${ }^{2}$ Italo Calvino also published the continuation of Qfwfq's adventures in The new cosmicomics (1995) which we will refer to here. 
order sought must be that in which regularity and tension contrapose and juxtapose themselves to maintain balance. We observe cubes, octahedrons, prisms and diaphanous figures. The order is like that of crystals, which are sculpted by time and lapidated by characteristics of vigor, impetus and tension.

The notion of an order by tension shows up when Qfwfq declares his love to Vug, a character who is a crystal. The crystal, to Qfwfq, is the image of perfection or the dream of material perfection; the reflected order (sculpted) in a mineral image. The contemplation of order makes Qfwfq admit that, sooner or later, the dream of perfection hampers and may also turn into smoke, unmaking itself "in a frayed patch of disaggregation" (Calvino, 1995, p. 44). That is when catastrophe appears. Everything crumbles. In face of the scenery of catastrophe, Qfwfq chooses, preferentially, order, for it fosters the feelings of fear and happiness. Happiness comes from the discovery that the substances are teleological. They seek perfection, particularly, an effective, useful and beautiful form. Fear, for perceiving in the variety of orders the growing scales of disorder. Scales which, sooner or later, will compromise the happiness of search.

Vug, the crystal woman, is the image-reflection of the world, with billions of sides and angles, according to Qfwfq. It is a solid destined to amplify itself in perspectives, transparencies, levels and sides. With order there may be no hoaxes, he says, one can't try to escape the drama of time or become obsessed with the idea of a perfect order. Qfw$\mathrm{fq}$ learns, bit by bit, the lessons of the crystal. Vug teaches him: "admitting that the true order is that which brings in itself the impurity, the destruction" (Calvino, 1995, p. 49).

In the tale "The crystals", Qfwfq narrates the remote times when he dated Vug and bought a watch. He intended to compare the movement of the hands to the movement of seasons, moons, cycles of life and death. To follow time orienting himself by the watch hands was important to keep himself in the game of the world and of men, where things are scheduled: take the train, get out at the correct station, get to work on time, regularly organize day to day life, meet appointments, are all kinds of chronometric time. But those hands may elude us about what time is. The hands indicate an error, Qfwfq observes, which feigns an order in dust, a regularity in the system, because all order, whichever it is, soon disintegrates. The watch helps to simulate an order and regularity where there is neither one thing or the other. With or without a watch, the order of time is crumbling. This is not shown by the hands of the watch. It is necessary to escape (he confesses in the story: "The implosion") that "which is running from the catastrophe of time". He recognizes: "all the path of time is directed towards a disaster in a direction or contrary direction, and its intersections do not form a net of lines regulated by trades and deviations, but in a plot, an entanglement" (Calvino, 1995, p. 129-130).

Time tells a story which is only possible to be perceived and unveiled if we register it by means of narration. We note, over its trajectory, that this same narration is weathered to the point where it must change constantly, to maintain its internal correlations and go on, or find an ending. Qfwfq particularly dedicates himself to the understanding of order through chaos. When associating order and Eros, he manages to approximate, at first glance, contradictory terms. We follow the misconception, he says, which associates 
Eros to disorder. The reason for this mistake lies in the fact that only in the dynamics propitiated by Eros is that order can be loved. The association between Eros and order hides the ambition for perfection and symmetry between divergent elements. The order appears entangled, simultaneously, by Eros and disorder. Eros, in its turn, is simultaneously order and chaos. The purity (of the crystal and of order) only is possible due to faults, ruptures and impurities. Only the dynamics of Eros (or the love for Vug) could have revealed this: the order-chaos pair is what makes us understand how it works, reorganizes and lapidates itself in a system such as the crystal. Even the purity of the crystal won't show the stain, the fault and the corrosion time exerts upon it. To continue to maintain the impetus of vigor, matter must operate in catastrophe and in degradation, what, in Qfwfq's view, is the same as lapidation. To trim rough edges means to polish form. The watch cannot time the plot of time nor the lapidation of the crystal. The time of the watch is not sharpened by the time of the crystal. Moreover, the watch may fall, break, rust or simply stop functioning. Qfwfq convinces himself that irregularities are a part of:

a regular structure a lot vaster, in which each asymmetry we thought we observed corresponded, in reality, to a network of symmetries so complicated that we couldn't grasp its existence, trying to calculate how many billions dihedral sides and angles this labyrinthian crystal must have. (Calvino, 1995, p. 49)

This notion of time described by Italo Calvino caught the attention of Ilya Prigogine, for whom the collection of narratives of The cosmicomics reminded him of the Arab tales in which each story connects to other stories. "The story of matter connects to the cosmological story, to the story of life in the story of matter. And, finally, in our own lives which are immersed in the stories of society" (Prigogine, 1996, p. 192). The author mentioned the book as an example of the "imagination of possibilities":

Italo Calvino wrote a delectable collection of Cosmicomics novels in which he imagined beings which live in a precocious stage of the universe. They come together and reminisce about the difficult stage in which the universe was so small their bodies filled it completely. The imagination of possibilities, the speculation of what may have been, is one of the fundamental signs of human intelligence. What would be of the history of physics if Newton had been part of this precocious community? He would have observed the birth and death of particles, the mutual annihilation of matter and anti-matter. The universe would have been revealed to him from the very beginning as a system very distant from equilibrium, with its instabilities and bifurcations. (Prigogine, 1996, p. 194)

While thinking with the "oracles of thermodynamics", Qfwfq presents us a universe which is far from balanced. The view of the protagonist, as we have seen, realigned from Vug's position, is that of an "order which brings destruction in itself". When consulting the oracles, interrogating them about the universe, he receives the answer which tells 
him that "time is a perpetual and irreversible catastrophe". Prigogine identifies in these space-time notions present in Qfwfq's Community, the bifurcations and imbalances of the universe. The elemental particles unsensitive to the actions of time, although acquiring a form, go through the temporal effect of degeneration.

It was Prigogine who first doubted, in the domains of scientific research, the hypothesis that time is an illusion. According to him: "it is Einstein who appears more frequently with the ambition to eliminate time" (Prigogine \& Stengers, 1997, p. 210). The negation of time has always been a temptation. "As much for Einstein, the physicist, as for Borges, the poet" (Prigogine, 1996, p. 197). To deny time means to deny one's own reality, considering it an illusion. "Time and reality are inexorably linked. To deny time might seem like a consolation or a triumph of human reason, but it is always a denial of reality". (Prigogine, 1996, p. 197). The conception that "time is an illusion" was incorporated in the fundamental laws of physics and, since then, disallows a distinction between past and future, which play different roles, not symmetric. It was up to the observer, whose role was highlighted by the quantic theory, to be responsible for the rupture of temporal symmetry, as explained by the physicist: "today physics no longer denies time. It recognizes the irreversible time of the evolutions towards equilibrium, the rhythmic time of structures whose pulse is fed by the worlds that cross it" (Prigogine \& Stengers 1997, p. 211).

There is more than one's acceptance of time; what occurs is a rediscovery of time, a thought that treats time as a modifying and dialogical element, by excellence, between science, culture and society. We may say that the literature of Marcel Proust, Jorge Luís Borges and Italo Calvino, considering these three masters only, is traversed by the idea of time. Such rediscovery also brought the guarantee that these notions, such as the one of the time-arrow or of catastrophe, possess a fundamental constructive role which provides the image of a universe in constant realization, evolutionary and asymmetric. It also reveals its narrative element, for time is constantly telling a story. This rediscovery is also of fundamental importance to Morin:

to only rehabilitate time is not enough; the new universe, when born, made us discover its complexity. Time is one and multiple. It's simultaneously continuous and fragmented, eventual, agitated by ruptures and jolts which break its string and eventually recreate it, in other sites, other strings. This time is, at the same time, the time of derivations and dispersions, the time of morphogenesis and of developments. (Morin 1987, p. 85)

In Prigogine's vision, the history told by the universe and that physics repeatedly seeks to decipher looks like a romance such as that of "One thousand and one nights" (Prigogine \& Morin, 1998, p. 232): an intricate chain of plots and internal times which traverses each body, be it a social group or a book. Each one is "constituted by a plurality of times branched in each other following subtle and multiple articulations" (Prigogine \& Stengers, 1997, p. 121).

The conclusions of Prigogine's formal researches presented in the books $A$ nova aliança [The new aliance] (Prigogine \& Stangers, 1997), and The end of certainty (Prigogine, 1996), show that the irresolution of the paradox of time persists. "The time in which we 
live is essentially irreversible, while in simple physical objects - a pendulum or a planetary system - the arrow of time cannot be seen" (Prigogine quoted in Pessis-Pasternak, 1993, p. 45). According to Prigogine, the awareness of this paradox first appears in the Darwinian theory, since this was the first to mention the evolution of organisms, hence, of irreversibility; then there is the emergence of the second principle of thermodynamics, formulated by Clausius ${ }^{3}$, in 1865, which deals with entropy in the universe. The two fundamental principles of thermodynamics are: [1] "the energy of the universe is constant" and [2] "the entropy of the universe grows towards a maximum". Nature shows us, he says, reversible and irreversible processes.

On one hand, there is the time of clocks, of trajectories of classical dynamics, the time of communication. This time is in some way external to us, which we emit and receive signs. It is a time we measure with our clocks, but which is not part of our living bodies. On the other hand, there is the structural time, which I call internal, marked by the irreversible and by fluctuations, next to Bergson's “invention-time”. (Prigogine quoted in PessisPasternak, 1993, p. 42)

The traditional chronology of the Big Bang theory presupposes the existence of time zero, from which cosmic clocks started to function. It is an event which physicists such as Hubert Reeves and Ilya Prigogine recommend to be seen with caution. This form of measuring time does not consider the possibility of a time before time zero. It is precisely this idea of time zero which feeds the plot of the romances by Italo Calvino. n the story "The crystals", Qfwfq's watch does not assure that the order of time be fixed in the scale of the three hands, in the same manner in which, in the story "Dawn", the character narrates the creation of the universe as an event emerging from a flash of light inside a preexisting space-time. In this aspect, Calvino, through the imaginary, and Prigogine, based on scientific research, are brought close together. "Time precedes existence. It is more natural to suppose that the birth of our universe is an event in the history of the cosmos and that we should, therefore, attribute to this a time that precedes our universe's own birth" (Prigogine, 1996, p. 169).

History, the living beings and society may no longer be reduced to a notion of a single time. Now the multiplicity of time is considered a creative factor, disruptor of the system; a disturbance which may generate as well as degrade things. Prigogine finds inspiration in the idea of clinamen, by Lucretius ${ }^{4}$. It is the disrupting element which announces the "turnabout" of the atoms of the world. This element is a source of instability which announces that the process and duty are constitutive of physical existence. A world in which living beings and apparently inanimate objects such as rocks, plastic and soap

\footnotetext{
${ }_{3}^{3}$ Rudolf Clausius (1822-1888) German physicist and mathematician, considered to be one of the founders of thermodynamics. In his most important article, The mechanical theory of heat, published in 1850, he exposes, for the first time, the basic ideas of the Second Law of Thermodynamics. In 1865, he introduced the concept of entropy.

4 Titus Lucretius Carus (99 a. C.). Poet and philosopher, lived 44 years. In De rerum natura, Lucretius introduces the theory that visible light was composed by tiny particles.
} 
interact in a dynamic manner and may be born, die and evolve. The irreversibility of time relates, therefore, to the levels of correlations and coherences of the system and considers its capacity for resisting and auto-organizing through this disturbing tension. The perspective that all things are submitted to small and large catastrophes, that is, to the instabilities of time, appear in Calvino's characters as an exhortation to an awareness and decision makings required by the exercise of freedom. Life choices are also irreversible.

\section{CATASTROPHE, CHAOS AND THE IMAGINARY}

As in literature, cinema also explores the "imagination of possibilities". The disaster films ${ }^{5}$ have already shown our humanity (and our planet) destroyed by wars (tribal, seasonal, interstellar), bombs, monsters, various cataclysms such as polar winters, volcanoes, meteors, natural and induced disasters. Cinema spectacularly shows crowds of people devastated in seconds, cities destroyed as if by magic and continents being torn in apart. What is the significance of this constant return to this theme by fiction and by speculative documentaries of Discovery Channel? TV news have become vultures which overfly misery, terrorist attacks, bugs, climatic changes, the 12-21-2012 - wherever there is catastrophe the media will be found. Why do we invest so much attention in this direction? How can we continue to look to the neo-messianism ${ }^{6}$ and the neo-sebastianism ${ }^{7}$ of our era which won't quit insisting that the end is near or the man "will return"?

The word "catastrophe" comes from the Greek language and literally means "turned upside down" (kata + sthophé). Another possible translation is "collapse", or "disaster"; or even in Hebrew Shoah, especially fit to the context. Catastrophe is, by definition, an event which provokes a trauma, another Greek word which means "wound". "Trauma" derives from an Indo-European language and has two meanings: "friction, grind, perforate"; but also "supplant", "go through". In this contradiction - something which grinds, perforates, but, at the same time, is what makes us supplant it, revealing, once more, the paradox of catastrophic experience, and for this reason is not easily captured by simple forms of narrative. (Nestrovski \& SeligmanSilva, 2000, p. 8)

We may, therefore, say that our imaginary, as with disaster films, behaves/collects/ provides feedback to the archetypical image of injury and wound, guards the "upside down" and the "trauma". The tragic wound may not be cured. It is in our archaic memory

\footnotetext{
${ }^{5}$ We call "disaster films" the set of movies produced with the theme of the destruction of humanity (or part of it) or of planet earth.

${ }^{6}$ Belief in the return of a divine emissary. Word that derives from Messiah (mashiah in Hebrew, christós in Greek). Term utilized to characterize movements or attitudes moved by the affection of "choice" or "election".

${ }^{7}$ Mystical-secular movement which occurred in Portugal in the second half of the $16^{\text {th }}$ century. With the disappearance of the King Philip II from the House of Habsburg. Sebastianism is a form of Messianism adapted to the Portuguese conditions and the Northeastern culture of Brazil. It means divergence with the situation of current politics and the prospect of salvation, even if it is a miraculous one.
} 
and, from time to time, resurfaces. Movies about the Holocaust have dominated the cinematographic imaginary of destruction of the $2 \mathrm{O}^{\text {th }}$ century to remind us that bad blood has flowed through the veins of the century. Cinema - agent of our archaic memory - revived and enacted pains we haven't been able to free ourselves from. Cinema and literature have also shown us our psychic life: the subjectivity and the affections. Moreover, the history of many of our artists is a history of madness, tragedies, sufferings, torments and despairs, therefore, themes of intimate catastrophe. Cinema and literature, in this sense, are two subjective infinites. They do not cease telling parabolas about the past and the future. It is about an old pedagogy of the present: the narrative as a revitalization of the essential. Art shows us that catastrophe transits from the cosmic sphere to the sphere of human interiority as if chaos were continuously renovating itself. Catastrophe "is in our environment", says Plato in Critias. With this we mean that the theme appears everywhere, like the cosmological themes. It is a singular and personal theme, and agrees with what Edgar Morin stated:

our universe is catastrophic from the beginning. From the formidable deflagration which gave birth to it, it is dominated by forces of displacement, disintegration, collision, explosions and of destruction. It is constituted in and by the genocide of antimatter by matter, and its terrifying adventure continue in the devastations, in the massacres and in the singular dilapidations. The exit is ruthless. Everything will die. (1997, p. 271)

In 2011, Lars Von Trier released the movie Melancholia, and once again we saw the "end of days". The movie depicts two sisters: a bride, Justine (Kirsten Dunst), and the other who is already a mother, Claire (Charlotte Gainsbourg), with her husband John (Kiefer Sutherland), in their familiar and interpersonal relations and in their mental dimensions. The action of the film takes place in two stages: the first, before the knowledge that the world will end, in Justine's failed marriage, which is the spotlight; the second, when the Apocalypse is almost a certainty, and the spotlight changes to the "collapse" of Claire's personal world. Von Trier opts to start the film precisely the moment Earth clashes, being destroyed, with Melancholia, an imaginary planet. He explained to the press that he did this precisely because he wanted to change the focus of the spectators' attention from the event itself to the subjective human scene. Justine (the bride) is a reference to the "Justine" of Marquis de Sade; the soundtrack of the movie is essentially "Tristan and Isolde", by Richard Wagner.

We see planet Earth being hit by another planet, called Melancholia. In the movie, the skepticism by science and media are evident, vision which is not shared by the women and horses who, in their intimacy with the cosmos, are able to see what is to come. There, like in Italo Calvino's romance, the catastrophe happens on the cosmologic level as well as on the personal level. In the movie, we see Justine (Kirsten Dunst) face the camera with sorrow in her eyes while dead birds fall around her; Claire (Charlotte Gainsbourg) carries her son with difficulty across the golf field. Kirsten, dressed as a bride, appears tied to yarn strands and is then carried by the current; a horse silently falls. 
Everything crumbles.

Cinema is impregnated by the pathos of the end. The Holocaust theme, for example, is a constant in world cinematography. Some dictators were also fascinated by cinematographic images. Adolf Hitler was one of them. Hans Jurgen Syberberg tells us, in the movie Hitler, a film from Germany (1978), that, until the war began, the Führer watched many movies every day. After the start of the war, only news filmed at the battle fronts. We learn that each regiment of the German army had its own propaganda organization, which had a cinematographic function. This action allowed that facts which occurred at the fronts be transformed into journalistic documentaries. In one of Joseph Goebbels' speeches, at the end of the war, we watch him say: "Sirs, in one hundred years they will show the movie which describes the staggering days we live now. Don't you want a role in this movie? Each one of you has the opportunity to choose your role" (Nap, 1977).

Hans Syberberg shows us that Germany lost the war, but Hitler triumphed, that is, he managed to impregnate or imprint his diabolical logic into this century, making politics an art for the masses. He saw in destruction a complete work of art. "Hitler was one of the most pretentious filmmakers", says Peter Pal Pelbart (2000, p. 178). According to Pelbart, Hitler, a film from Germany, is not a documentary about a catastrophe, but about a catastrophe which was produced as a movie, a catastrophe with mise-en-scène, like a political cinematographic mega production of the Third Reich.

The films Melancholia and Hitler, a film from Germany resume the thematic string of catastrophe in our time through cinematography updating the archaic memory of catastrophe. As with art, science and philosophy also update our archaic memory, as we can see in proposals such as the Theory of Chaos or the Theory of Catastrophe by René Thom (1983), the Theory of Complexity by Edgar Morin (1987), in addition to the Theory of Media by Vilém Flusser. It is pertinent to note that this last one, in Vampyroteuthis infernalis (2011), called "the three catastrophes" the process of humanization, civilization and "media hurricane" (although saying that this third moment is still unnamed), he obviously refers to the field of information, press, advertising, cinema, that is, the 'fast and furious' exchanges of the mediatic-cultural systems. The first catastrophe was humanization, the descent from the trees, the becoming bipeds and erect, the nomad relocations throughout Earth. The second catastrophe was civilizational, the creation of villages and cities, around which the men were domesticated and began to plant vegetables and raise chicken. In Latin, the verbs sedere (sit) and possedere (possess) are brothers and clearly show proximity between sitting and possessing. Ten thousand years after the first settlements writing emerges and thus the logical systems which spring from it. We now live the advent of the third great catastrophe, which forces us to navigate, surf, wander, travel, ultimately escape through virtual networks, through synthetic landscapes and scenery, rectangular environments and through visual and sound imagery of media.

The imaginary of catastrophe brings us to opposing and complementary imaginaries: from finite to infinite. About the imaginary of the finite we find some image-ideas grouped in the representations of entropy, of death, of disappearance, of the graveyard, of the grave, of the abyss, of the sunset and of absolute immanence. In the imaginary of 
the infinite we have other images: the $\infty$ (lemniscate $\left.^{8}\right)$, which is Ouroboros ${ }^{9}$ duplicated $(\mathrm{O}+\mathrm{O})$, the snake that devours its own tail, representation of the continuous and perpetual movement, the image of liberty, of open spaces, of the impossibility of registry of things like the grains of sand, leaves and stars. These imaginaries (finite and infinite) oppose and complement each other and reveal the two meanings of catastrophe: the negative, entropy, end, conclusion; and the positive, supplantation, creation, and undetermined recreations.

We don't want the end to be close, we suffer from the agony of conclusions. That which therapists call the procrastination syndrome ${ }^{10}$. What Nestrovski and SeligmanSilva called "paradox of catastrophe" announces the presence of trauma, the echo of pain and wound, but also the overtaking and transcendence. This paradox reveals our immense capacity of starting from scratch. The word chaos derives from Káos, Khraíen, which means to open, open up. "It means unfathomable abyss, concept followed by a sign sphere which personifies it as a primordial emptiness, prior to creation, that is, as a rudis indigestaques moles - formless and confusing mass - capable of containing the seed of all things" (Naves quoted in Castro, Galeno \& Silva, 2003, p. 82).

Chaos (like catastrophe) takes the foundation and substitutes it. Catastrophe brings uncertainty and the "upside down". Our civilization seems to suffer from what Peter Sloterdijk (2012) called the "catastrophilia complex". It means a psycho-political symptom of suffocation of the social atmosphere which takes our time to the insufferable limit with schizoid and ambivalent tensions. We start to face reality as paranoia, as a collective disturbance of the vital feeling, by which the energies of life dislocate towards the sympathy by what is catastrophic, apocalyptic and endowed of spectacular violence.

Literature, cinema, arts and media show us, as a whole, that we are submitted to affective, informational and conscience storms which seize the great public, through explosions of happiness, violence and, sometimes - as happens in Brazil during World Cups - national emotion; in other moments, the great public seizes the pleasure of agony, drunkenness of destiny and religious happiness. The ideas of happiness and success are forms of running from failure. The "catastrophilia complex" corroborates the pathos of the end, this incapacity of concluding the systematic attitude of "procrastination" even when these jobs become urgent and unavoidable.

The information volume of media is imposed upon us like a form of conscience which learns how to choose scandal as a lifestyle and catastrophe as background noise, says Peter Sloterdijk (2012, p. 412). An example: when we think of criminal issue as it is placed in our society, but also in the manner which is placed in the ambit of arts

\footnotetext{
8 From the Latin Lemniscus: suspended band. Curve which has a curve similar to the number 8 and is the symbol of infinity. The reason for this geometric curve to assume such a meaning is due to its continuous line.

9 Ouroboros (or oroboro or yet uróboro) is a symbol represented by a snake, or a dragon, which devours its own tail. The name comes from ancient Greek: oúpó (oura) means "tail" and ßópoৎ (boros), which symbolizes eternity. It's related to alchemy and is, at times, represented by two mythical creatures devouring each other's tails. It is possible that the mathematical symbol of infinity $(\infty)$ originated by the image of two ouroboros, side by side.

${ }^{10}$ Refers to the incapacity of concluding. Systematic attitude of "procrastination" even when these jobs become urgent and unavoidable.
} 
- literature, theater and cinema - we are faced with various criminal schemes, which give us the impression of depletion of forms of imagining torture, assassinations, dismemberments, and various forms of violence. We constantly create, each day, forms of tension; tense situations, which no longer wish to be communicated and dissolved, but thrown in the wind. The tragic was dislocated to the world of journalism, without completely exiting the artistic field, like we see in the reincarnation of Greek tragedies and in the disaster films.

\section{THE END WHICH IS A NEW START: CONCLUSION}

Our objective in this article is to note how the notion of time in literature and movies may come closer to that of physics and how both subsidize a perceptive/aesthetic mode of mediation with the world such as chaos and order. We saw how the notion of time is a mediator of the comprehension of space/time reality, be it from the scientific point of view (physical), be it from the artistic point of view (fictional). The "imagination of the possibles" by Calvino, described by Prigogine, reveals a founding trait of conceptual opening and of the exercise of transdisciplinarity and, therefore, a trace of human intelligence. The imagination of Italo Calvino depicted a narrative in which space and time diluted in an anamorphic, dynamic, floating and auto-organized mode. The form is like Qfwfq's form, it continuously changes, at times advancing in complexity, at times not. These narratives, written throughout the 1970's, hold an image-idea of communication and media which accompanies this fluctuation, dynamics, movement and uncertainty. In this sense, it is up to the media, whichever it is, to house in its logic the confusing ("bruit"), chaotic or catastrophic, not like a noise which only creates disorder, but also, necessarily, as a new organization which is only possible to be reached due to the capacity of mediation (or of "interaction") of the system.

To conclude, we assert he idea that the recalling of catastrophe is a constant in art, in cinema and in culture, because it is an intimate obsessive theme. We fall prey to the fear of the end. The spirit of death seems to haunt only those who weren't marked by the scar of finitude. Finitude is, therefore, a question of transcendence. We hold in our memories that which Edgar Morin called "painful destiny" (2013). Conscient life is frail and minoritarian in the universe; it holds the information and remote memory of this fragility. For Edgar Morin, we observe chain catastrophes in economy, in the biosphere, in the multiplication of weapons of mass destruction, in the ethno-religious convulsions. We don't live just one catastrophe, but a set of movements with tendency towards unbalance and instability. We understand that the imaginary of catastrophe, seen through literature, cinema, arts and communication, is a separate emotional infinite. Italo Calvino has shown us the resilience, the capacity of adaptability and of human resistance in face of time and chaos.

Our second conclusion is that the theme of catastrophe partially caters for some of the affection for horror of current humanity. It is an imaginary which must be continuously updated, revisited, reexplored, to move us in the direction of the need for rebirths. 
The third conclusion is that the imaginary of catastrophe is not recent, is not individual, is not national, but collective, transcultural and, in some sense, affectionatepoetic and magical. Catastrophe produces a chain of affections which goes from terror to piety. There is inside it a permanent and active instability. Day and night, acts like a principle of convulsion and harmony between the universal laws and particular cases, between gods and men, between forms of nature and forms of culture, between objects of the world and thinking beings. The importance of this instability lies in the fact that it appears to be the motor of actions. We know that the real catastrophe is not when there is movement, but on the contrary, when everything is stagnated, without creativity, without sense, with no ground. Human capacity of imagining and creating the worse has no limits. But the opposite is also true. To run away from chaos towards a "crystal order", towards Eros or towards Vug's love is a form of realizing beauty.

\section{REFERENCES}

Atlan, H. (1992). Entre o cristal e a fumaça. Ensaio sobre a organização do ser vivo. Rio de Janeiro: Jorge Zahar Editor.

Baitello Jr, N. (2012). Pensamento sentado. Sobre glúteos, cadeiras e imagens. São Leopoldo: Ed. Unisinos.

Calvino, I. (1992). As cosmicômicas. São Paulo: Companhia das Letras.

Calvino, I. (1995). Novas cosmicômicas. Lisboa: Teorema.

Flusser, V. (2011). Vampyroteuthis infernalis. São Paulo: Annablume.

Castro, G., Galeno, A. \& Silva, J. (2003). Complexidade à flor da pele. São Paulo: Cortez.

Garde, P. (Produtor) \& Von Trier, L. (Realizador). (2011). Melancholia [Film]. Germany/Denmark/France/ Sweden.

Maza, A. J. P. (2015). O poder expressivo da teoria dos mundos possíveis nos videojogos: quando as narrações se convertem em espaços interactivos e fictícios. Comunicação e Sociedade, 27, 273-277. http://dx.doi.org/10.17231/comsoc.27(2015).2101

Morin, E. (1987). O método I - A natureza da natureza. Lisboa: Europa América.

Morin, E. (1997). Meus demônios. Rio de Janeiro: Bertrand Brasil.

Morin, E. (2013). Meus filósofos. Porto Alegre: Sulina.

Nap, H. (Produtor) \& Syberberg, H. (Realizador). (1977). Hitler - um filme da Alemanha [Film]. BBC London.

Naves, D. (2003). Caos, filosofia e ciência. In G. Castro, J. Silva \& A. Galeno, Complexidade à flor da pele (pp. 81-94). São Paulo: Cortez.

Nestrovski, A. \& Seligman-Silva, M. (2000) Catástrofe e representação. São Paulo: Escuta.

Pelbart, P. P. (2000). Cinema e holocausto. In A. Nestrovski \& M. Seligman-Silva, Catástrofe e representação (pp. 171-183). São Paulo: Escuta.

Pessis-Pasternak, G. (1993). Do caos à inteligência artificial. São Paulo: Unesp. 
Platão (2010). Timeu - Crítias. São Paulo: Annablume.

Prigogine, I. (1996). O fim das certezas. São Paulo: Unesp.

Prigogine, I. (1993). Ilya Prigogine: o arquiteto das "estruturas dissipativas". In G. Pessis-Pasternak, Do caos à inteligência artificial (pp. 35-50). São Paulo: Unesp.

Prigogine, I. \& Morin, E. (1998). A sociedade em busca de valores. Lisboa: Instituto Piaget.

Prigogine, I. \& Stengers, I. (1997). A nova aliança. Metamorfose da ciência. Brasília: UnB.

Romano, V. (1993). Desrollo y progresso. Por una ecología de la comunicación. Barcelona: Teide.

Sloterdijk, P. (2012). Crítica da razão cínica. São Paulo: Estação Liberdade.

Thom, R. (1983). Paraboles et catastrophes. Paris: Flammarion.

Weaver, W. (1948). Science and complexity. American Scientist, 36, 536-544.

\section{BIOGRAPHICAL NOTES}

Gustavo Castro is a poet, writer and journalist. Senior Internship (2015) in Iberian and Latin American studies at the University of Sorbonne-Paris IV (Bolsa Capes); Postdoctorate (2011) in literary theory from the University of Brasilia (UnB); PhD (2002) in anthropology from the Pontifical Catholic University of São Paulo (PUC-SP), with a thesis on the writer Italo Calvino (Bolsa Capes). Master's degree in Education (CNPq Scholarship in educational Technology) by UFRN (1997). Volunteer researcher at the Institute of Brazilian Studies, University of São Paulo (IEB-USP). It studies the imaginary in the perspective of complex thinking. Member of the thematic axis Études Lusophones (EL), of the Centre de Recherches Interdisciplinaires sur le Monde Ibériques Contemporains (Crimic/Sorbonne). He coordinates the group Siruiz-Study in communication and literary production (http://siruiz.com/), at the University of Brasilia, where he is professor of aesthetics in the Faculty of Communication. He is currently dedicated to the project "biographic profile of João Guimarães Rosa (1908-67)". He is the author of "The Enigma Orides" (Ed. Hedra, 2015), about the poet Orides Fontela (1940-1998), among others.

ORCID https://orcid.org/0000-0001-7126-6947

Email: gustavodecastro@unb.br

Address: QNL o7 Conjunto J, Casa 7, Taguatinga Norte, Brasília - DF / 72150-710

Florence Dravet is a cosmetic writer at the Catholic University of Brasilia. $\mathrm{He}$ is a $\mathrm{PhD}$ in didactology of languages and cultures, with a thesis in Intercultural communication, at the University of Paris III-Sorbonne-Nouvelle (2002). He did post-doc in communication, from the University of Brasilia, (2011). Currently she is coordinator of the Graduate program in communication of the Catholic University of Brasilia. Member of the editorial board of Spheres magazine and the magazine Comunicologia. She studies the phenomena of sensibility, of the imaginary, of the feminine, of the body and of the 
poetic, the Afro-Brazilian traditions and the transculturality. He coordinates the group of studies in communication, language and poetry of CNPq. It is masquerade of the books "under the Sky of Culture" (Brasilia, Thesaurus, Casa das Musas, 2008) and "Knowledge of communication" (Brasília, Casa das Musas, 2010). She is the author of the books: "Critique of the metaphorical reason-myth, magic and poetry in Contemporary Culture" (Brasília, Casa das Musas, 2014) and "Communication and Poetry" (Brasília, UnB, 2014). She has also several books of poetry.

ORCID: https://orcid.org/oooo-0002-3822-3627

Email: flormd@gmail.com

Address: Avenida Jacarandá, Lote 22, Apto. 1011, Águas Claras, Brasília - DF / 71927-540

* Submitted: 02/08/2018

* Accepted: 19/11/2018 